\title{
BRCA1/2 normal meme kanserli kadınlarda genotip-fenotip ilişkisinin araştırılması: Türkiye'den tek merkez deneyimi
}

\section{Investigation of genotype-phenotype relationship in women with BRCA1/2 normal breast cancer: A single-center experience from Turkey}

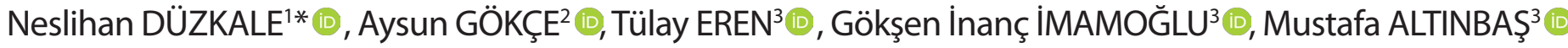

${ }^{1}$ Ankara Dışkapı Yıldırım Beyazıd Eğitim ve Araştırma Hastanesi, Tıbbi Genetik Bölümü, Ankara/TÜRKIYE ${ }^{2}$ Ankara Dışkapı Yıldııım Beyazı d Eğitim ve Araştırma Hastanesi, Tıbbi Patoloji Bölümü, Ankara/TÜRKIYE ${ }^{3}$ Ankara Dışkapı Yıldııım Beyazıd Eğitim ve Araştırma Hastanesi, Tıbbi Onkoloji Kliniği,, Ankara/TÜRKIYE

\section{öz}

Amaç: Meme kanserlerinin yaklaşık \%10'unun kalıtsal olduğu ve bunların yaklaşık \%20'sinden BRCA1/2 genlerinin sorumlu olduğu bilinmektedir. Yapılan araştırmalar, meme kanserinde BRCA1/2 dışındaki birçok genin mutasyonlarının da yatkınlığa neden olduğunu göstermiştir. Bu çalışmada meme kanserli kadınlarda diğer kanser yatkınlık genlerinin araştııılması amaçlanmıştır.

Gereç ve Yöntemler: Bu retrospektif çalışmaya Ankara Dışkapı Yıldırım Beyazıt Eğitim ve Araştırma Hastanesi Genetik Bölümü'nde 2016-2020 yılları arasında değerlendirilen 66 kadın hasta dahil edildi. Hastaların kansere yatkınlık genleri, yeni nesil dizileme tekniği (NGS) kullanılarak incelendi.

Bulgular: Hastaların ortalama tanı yaşı $43 \pm 8.0$ idi. Genetik analiz ile 66 hastanın 9'unda $(\% 13,63)$ nedensel gen tespit edildi. Bu genler ATM (\%11), BRIP1 (\%11), CHEK2 (\%34), FANCC (\%11), MUTYH (\%11) ve PALB2 (\%22). Nedensel varyant। olan hastalar ve diğerleri gruplandırılarak tanı yaşı, tümör lokalizasyonu, tümörün histopatolojik tipi, östrojen/progesteron reseptör durumu, c-erbB2, evre, tanı anındaki metastaz ve kanserli akraba sayısı gibi parametreler açııından karşılaştıııldı. Gruplar arasında istatistiksel bir ilişki bulunamadı.

Sonuç: Bu çalışmada Tıbbi Genetik bölümümüze başvuran meme kanserli kadınlarda BRCA1/2 dışındaki kansere yatkınlık genlerinin nedensel varyantlarının saptanma oranı \%13,63 olarak belirlendi. Kanserli bireylerde NGS ile çoklu gen testlerinin yapılması, taşıyıcı bireylerin doğru tanı ve uygun tedavi almalarını ve gerekli taramalara yönlendirilmelerini sağlayacaktır.

Anahtar Kelimeler: Meme kanseri; BRCA1/2; kalıtsal kanser yatkınlık genleri; yeni nesil dizileme; çoklu gen paneli

Sorumlu Yazar*: Neslihan DÜZKALE, Ankara Dışkapı Yıldırım Beyazıd Eğitim ve Araştırma Hastanesi, Tıbbi Genetik Bölümü, Ankara/TÜRKiYE 


\section{ABSTRACT}

Aim: It is known that approximately $10 \%$ of breast cancers are hereditary, and BRCA1/2 genes are responsible for approximately $20 \%$ of these. Studies have shown that mutations of many genes other than BRCA1/2 in breast cancer also cause this predisposition. In this study, it was aimed to investigate other causative cancer susceptibility genes in women with breast cancer.

Material and Methods: In this retrospective study, 66 female patients who were evaluated in Ankara Dışkapı Yıldırım Beyazıt Training and Research Hospital Genetics Department between 2016-2020 were included. Cancer susceptibility genes of the patients were examined using next-generation sequencing technique (NGS).

Results: Mean age at diagnosis of the patients was $43 \pm 8.0$. By genetic analysis, causative genes were identified in 9 (13.63\%) of 66 patients. These genes are ATM (\%11), BRIP1 (\%11), CHEK2 (\%34), FANCC (\%11), MUTYH (\%11) and PALB2 (\%22). Patients with a causal variant and others were grouped, and compared in terms of parameters such as age at diagnosis, tumor localization, histopathological type of tumor, estrogen/progesterone receptor status, c-erbB2, stage, metastasis at diagnosis, and number of relatives with cancer. No statistical relationship was found between the groups.

Conclusion: This study determined the rate of detection of causal variants of cancer susceptibility genes other than BRCA1/2 in women with breast cancer who applied to the medical genetics department as $13.63 \%$. Performing multiple gene tests with the NGS in cancer individuals will allow carrier individuals to receive correct diagnosis and appropriate treatment and to be directed to necessary screenings.

Keywords: Breast cancer; BRCA1/2; hereditary cancer susceptibility genes; next generation sequencing; multi-gene panel

\section{Giriş}

Meme kanseri kadınlar arasında en sık görülen neoplazi türü olup, aynı cinsiyette kanser nedeniyle olan ölümlerin önde gelen nedenlerinden biridir. Meme kanserinin dünya genelindeki yıllık insidansının tahminen 1,4 milyon olduğu ve bunların yaklaşık üçte birinin ise kanser nedeniyle öldüğü bildirilmiştir [1]. 19. yüzyılın ortalarında meme kanserlerinin ailesel kümelenmelerinin tanımlandığı raporun bildirilmesinden buyana, günümüzde tüm meme kanserlerinin \%5-10'unun kalıtsal olduğu kabul edilmektedir. Pozitif aile öyküsü, meme kanserinin kalıtsal türünün gelişiminde en önemli risk faktörlerinden biridir. Meme kanser ailelerinde genellikle dominant bir kalıtım paterni hakimdir ve bireylerde erken tanı yaşı, kanserin bilateral olması, over kanseri ve erkek cinsiyet meme kanserinin artmış sıklığı gözlenmektedir $[2,3]$. Popülasyon temelli epidemiyolojik çalışmalarda, ailesel meme kanseri vakalarının yalnızca \%16-20'sinde, BRCA1ve BRCA2 genlerinin sorumlu olduğu gösterilmiştir [4]. Yüksek penetranslı BRCA1/2 genlerinden başka; TP53, CDH1, PTEN, STK11, RAD51C, RAD51D gibi diğer yüksek penetranslı genler ve ATM, CHEK2, BRIP1, PALB2 gibi düşük/orta penetranslı genler de, ailesel meme kanseri hikayesine sahip olgularda nedensel olabilmektedir. Bu genler çoğunlukla, genomik bütünlüğün ve DNA onarım mekanizmalarının sürdürülmesinde rol oynamaktadır [5]. Bu çalışmada, meme kanseri tanısı almış ve $B R C A 1 / 2$ genlerinde nedensel varyant saptanmayan kadınlarda, meme kanserine yatkınlık oluşturabilecek diğer genlerin araştırılması amaçlanmıştır.

\section{Gereç ve Yöntemler}

Bu retrospektif kohort çalışmasına, 2016-2020 yılları arasında Ankara Dışkapı Yıldırım Beyazıt Eğitim ve Araştırma Hastanesi Genetik Bölümü'nde değerlendirilmiş olan, 18 yaşından büyük, aralarında akrabalıkbulunmayan ve meme kanseritanılı 66 kadın hasta dahil edilmiştir. Hastaların tamamı Ulusal Kapsamlı Kanser Ağı (NCCN) kılavuzlarının yönergeleri doğrultusunda BRCA1/2 gen testi için yeterli kriterleri sağlamış ve yeni nesil dizileme (NGS) tekniği kullanılarak sözkonusu genler incelenmiştir [6].

Bu analiz sonucunda normal olarak değerlendirilen hastalarda, BRCA1/2 genlerindeki olası geniş genomik yeniden düzenlenmelerin değerlendirilmesi amacıyla, multipleks ligasyon bağımlı prob amplifikasyonu (MLPA) tekniği ile delesyon/duplikasyon araştırmaları yapılmıştır. Araştırmaya dahil edilen veBRCA1/2 gen analizlerinormal olaraksonuçlanmış olan 66 hastada BRCA1/2 dışında diğer kanser yatkınlık genleri incelenmiştir. Hastaların demografik özellikleri, klinik detayları ve tümörlerinin histopatolojik bulguları detayları ile ilgili bilgiler, hasta dosyaları ve tıbbi kayıtlarından retrospektif olarak elde edilmiştir. Tüm hastaların meme kanseri tanıları histolojik olarak doğrulanmış ve evreleme, Amerikan Ortak Kanser Komitesi'nin (AJCC) altıncı baskısına göre belirlenmiştir [7]. 
İmmünohistokimya (IHK) ile pozitif boyanan hücreler \%1'den daha az ise östrojen ve progesteron reseptör durumları negatif olarak değerlendirilmiştir. İHK boyamasında c-erbB-2 (HER-2/ neu) gen amplifikasyonu için membranöz boyama, 0'dan +3'e derecelendirilmiş ve boyama modeli + 2 olan hastalar, floresan in situ hibridizasyon yöntemi kullanılarak tekrar değerlendirilmiş ve HER2 geninin <2 kopyası negatif kabul edilmiştir.

Hastaların üç kuşak pedigri analizlerinden kanserli akraba sayısı ve akrabalardaki kanserlerin türleri incelenmiştir. Bu çalışma, Helsinki Bildirgesi'ne göre etik sorumluluklar dikkate alınarak yapılmış ve bağımsız bir etik kurul tarafından onaylanmıştır. Bu çalışmaya katılan tüm hastalar, çalışma ile ilgili bilgilendirilmiş ve yazılı onamları alınmıştır.

\section{Etik Beyannamesi}

Çalışmaya katılan hastalardan, çalışma ile ilgili tüm verilerin yayınlanması için çalışma öncesinde yazılı bilgilendirilmiş onam alınmıştır. Bu çalışma Dünya Tabipler Birliği ve Helsinki Bildirgesi'ne göre etik sorumluluklar dikkate alınarak yapılmış ve bağımsız bir Etik Kurul tarafından onaylanmıştır.

\section{Genetik Analiz}

Hastaların periferik venöz kan örneklerinden DNA ekstrakte etmek için QIAcube ${ }^{\circledR}$ otomatik izolasyon sistemi (Qiagen Inc. Mississauga, Kanada) kullanılmıştır. Kalitesi ve konsantrasyonu spektrofotometrik olarak değerlendirilen ve uygun bulunan DNA örnekleri (OD260/OD280, 1.8-2.0) NGS çalışmasına dahil edilmiştir. Dizileme işleminde kullanılan platform, Illumina MiSeq sistemidir (Illumina Inc., San Diego, CA, ABD).

Bu çalışmada 59 gen içeren Qiagen geniş kalıtsal kanser paneli (Qiagen, Hilden, Almanya) ve 27 gen içeren Kalıtsal Kanser Solusyon v1.1 paneli (Sophia Genetics, Saint-Sulp) kullanıldı. 59 gen içeren geniş panelde; AIP, APC, ATM, ATR, AXIN2, BAP1, BARD1, BLM, BMPR1A, BRCA1, BRCA2, BRIP1, BUB1B, CDH1, CDK4, CDKN2A, CHEK2, CTNNA1, EPCAM, FAM175A, FANCC, FLCN GALNT12, GEN1, GPC3, GREM1, HOXB13, MET, MLH1, MRE11A, MSH2, MSH6, MUTYH, NBN, NTHL1, PALB2, PALLD, PIK3CA, PMS1, PMS2, POLD1, PRSS1, PTCH1, PTEN, RAD50, RAD51B, RAD51C, RAD51D, RET, RINT1, SDHB, SDHC, SDHD, SMAD4, SMARCA4, STK11, TP53, VHL, XRCC2 genleri mevcuttu. 27 gen içeren panel ise; ATM, APC, BARD1, BRCA1, BRCA2, BRIP1, CDH1, CHEK2, EPCAM, FAM175A, MLH1, MRE11A, MSH2, MSH6, MUTYH, NBN, PALB2, PIK3CA, PMS2, PMS2CL, PTEN, RAD50, RAD51C, RAD51D, STK11, TP53, XRCC2 genlerini kapsiyordu.

Analiz sonucunda elde edilen verilerin analizinde; Qiagen geniş kalıtsal kanser paneli için QIAGEN Clinical Insight $\left(\mathrm{QCI}{ }^{\mathrm{TM}}\right)$ yazılımı (QIAGEN, Hilden, Almanya) ve Kalıtsal Kanser Çözümü v1.1 paneli için Sophia DDM yazılımı (Sophia Genetics, SaintSulp) kullanıldı. Araştırılan genlerin eksonik bölgelerine ek olarak, ekson-intron sınırındaki intron bölgelerinde de 20 baz çifti değerlendirildi. Çalışmada tespit edilen varyantlar, Amerikan Tıbbi Genetik ve Genomik Koleji (ACMG) kılavuzundaki kriterlere göre sınıflandırıldı [8].

\section{İstatistiksel analiz}

İstatistiksel analiz için IBM SPSS 25 (Statistics Programme for Social Scientists) (USA) programı kullanıldı. Verilerin normal dağılıma uygunluğu için Kolmogorov Smirnov testi kullanıldı. Normal dağılıma uymayan sürekli veriler ortanca (aralık) olarak, kategorik veriler ise frekans (yüzde) olarak verildi. Bağımsız gruplar arasında normal dağılıma uymayan iki grup verilerinin karşılaştırılmasında Mann Whitney U testi kullanıldı. Bağımsız kategorik değişkenlerin karşılaştırılmasında ki-kare veya Fisher'ın Exact testi kullanıldı. Bu çalışmada istatistiksel analizler iki yönlü uygulandı ve $\mathrm{p}<0.05$ istatistiksel olarak anlamlı kabul edildi.

\section{Bulgular}

Bu çalışmaya dahil edilen 66 hastanın yaş ortalaması $49 \pm 10,4$ (ortanca: 47 (26-77)) ve ortalama tanı yaşı ise 43 $\pm 8,0$ (ortanca: 42 (24-69)) idi. Hastaların demografik ve klinikopatolojik özellikleri Tablo 1'de verilmiştir. Genetik analizi gerçekleştirilen 66 hastadan 9'unda meme kanserine yatkınlık oluşturan çeşitli genlerde heterozigot durumda, patojenik ve muhtemel patojenik varyantlar tespit edildi (Tablo 2). Nedensel genler, 3 (\%34) hastada CHEK2, 2 (\%22) hastada PALB2 ve 1'er hastada (\%11) ATM, MUTYH, FANCC ve BRIP1 genleri olarak saptandı (Şekil 1). Yapılan genetik analiz ile mutasyonların tespit edilme oranı \%13,63 (9/66 hasta) olarak tespit edildi. Bu nedensel varyantlardan \%44,4 (4/9 hasta)'u 59 gen içeren panel ile \%55,6 (5/9 hasta)'u 27 gen içeren panel ile saptandı. 22 hastanın araştırılan genlerinde klinik önemi bilinmeyen varyantlar (VUS) olmasına rağmen hastalıklarının genetik arka planı aydınlatılamadı ve bu hastalar ilişkili VUS'ların netleşmesi amacıyla periyodik yeniden değerlendirme programına (ilgili VUS'un belirli intervallerle (6 ay-1 yıl) yeniden sınıflandırılması işlemi) dahil edildi. Kalan 35 hastanın araştırılan genleri normal olarak değerlendirildi.

Çalışmada nedensel varyantları taşıyan ve taşımayan hastalar istatistiksel karşılaştırma için ayrı ayrı gruplandırıldı. Bu gruplar arasında yaş, tanı yaşı, primer tümörün lokalizasyonu, tümörün histopatolojik tipi, östrojen/progesteron reseptör pozitiflik durumu, c-erbB2 skoru, grade, tanı anı metastaz, meme kanserli akrabaların sayısı ve kanserli (tüm türler) akraba sayısı açısından istatistiksel olarak anlamlı bir ilişki bulunamadı (Tablo 3). 


\begin{tabular}{|c|c|}
\hline Değişken $(n=66)$ & Birey sayısı (\% değer) \\
\hline \multicolumn{2}{|l|}{ Genetik analiz sonuçları } \\
\hline Patojenik/Likely patojenik & $9(13,4)$ \\
\hline VUS & $22(33,2)$ \\
\hline Normal & $35(53,4)$ \\
\hline \multicolumn{2}{|l|}{ İlk prezentasyon } \\
\hline Rutin kontrol & $13(19,7)$ \\
\hline Ele gelen kitle & $53(80,3)$ \\
\hline \multicolumn{2}{|l|}{ Tümör yerleşimi } \\
\hline Sağ meme & $33(50,0)$ \\
\hline Sol meme & $32(48,5)$ \\
\hline Bilateral meme & $1(1,5)$ \\
\hline \multicolumn{2}{|l|}{ Histopatolojik sonuç } \\
\hline İnvaziv duktal & $47(71,2)$ \\
\hline DCIS & $9(13,4)$ \\
\hline İnvaziv lobüler & $1(1,5)$ \\
\hline LCIS & $1(1,5)$ \\
\hline Mix & $5(7,6)$ \\
\hline Müsinöz & $2(3,0)$ \\
\hline Papiller & $1(1,5)$ \\
\hline \multicolumn{2}{|l|}{ Östrojen reseptörü } \\
\hline Pozitif & $57(86,4)$ \\
\hline Negatif & $9(13,6)$ \\
\hline \multicolumn{2}{|l|}{ Progesteron reseptörü } \\
\hline Pozitif & $54(81,8)$ \\
\hline Negatif & $12(18,2)$ \\
\hline \multicolumn{2}{|l|}{ C-erbB2 skor } \\
\hline 0 & $12(18,2)$ \\
\hline 1 & $9(13,6)$ \\
\hline 2 & $13(19,7)$ \\
\hline 3 & $32(48,5)$ \\
\hline \multicolumn{2}{|l|}{ Derece (Grade) } \\
\hline 1 & $8(12,1)$ \\
\hline 2 & $25(37,9)$ \\
\hline 3 & $33(50,0)$ \\
\hline \multicolumn{2}{|l|}{ Tanı anı metastaz } \\
\hline Yok & $44(66,7)$ \\
\hline Var & $22(33,3)$ \\
\hline \multicolumn{2}{|l|}{ Medeni hali } \\
\hline Bekar & $10(15,2)$ \\
\hline Evli & $51(77,3)$ \\
\hline Dul & $5(7,6)$ \\
\hline \multicolumn{2}{|l|}{ Çocuk sayısı } \\
\hline Yok & $13(19,7)$ \\
\hline $1-2$ & $42(63,6)$ \\
\hline 3 ve üzeri & $11(16,7)$ \\
\hline \multicolumn{2}{|c|}{ Akrabalarda yalnız meme kanserli birey sayısı } \\
\hline Yok & $17(25,8)$ \\
\hline $1-2$ çocuk & $38(57,6)$ \\
\hline 3 çocuk ve üzeri & $11(16,7)$ \\
\hline \multicolumn{2}{|c|}{ Akrabalarda kanserli birey sayısı (tüm kanser türleri) } \\
\hline 0 & $1(1,5)$ \\
\hline $1-2$ & $18(27,3)$ \\
\hline $3-5$ & $39(59,1)$ \\
\hline 6 ve üzeri & $8(12,1)$ \\
\hline
\end{tabular}

Verilerin normal dağılıma uygunluğu için Kolmogorov Smirnov testi kullanıldı. Normal dağı̆ıma uymayan sürekli veriler ortanca (aralık) olarak, kategorik veriler ise frekans (yüzde) olarak verildi. 
Tablo 2: Çalı̧smada tespit edilen tüm gen varyantlan.

\begin{tabular}{|c|c|c|c|c|c|c|c|c|c|}
\hline$I D$ & Gen & Nük/AA Değiz̧imi & $\begin{array}{c}\text { Varyant } \\
\text { tipi }\end{array}$ & $A C M G$ & Yaş & Tanı yaģı & $d b S N P$ & \multicolumn{2}{|c|}{ Akrabalarda kanser ōykūsü } \\
\hline \multirow[b]{2}{*}{ P5 } & \multirow[b]{2}{*}{$X R C C 2$} & & \multirow[b]{2}{*}{ MS } & \multirow[b]{2}{*}{ vUS } & \multirow[b]{2}{*}{60} & \multirow{2}{*}{39} & \multirow[b]{2}{*}{ - } & $I^{5}$ & $1 \mathrm{Bra}, 1$ Colon \\
\hline & & $\begin{array}{l}\text { C. } 450 \mathrm{C} \text { A } \\
\text { p.(Ser150Arg) }\end{array}$ & & & & & & & $\frac{1 \mathrm{Bra}}{3 \mathrm{Bra}_{\mathrm{ra}}}$ \\
\hline \multirow{3}{*}{$\mathrm{p} 7^{*}$} & \multirow{3}{*}{ BRIPI } & & \multirow{3}{*}{ FS } & \multirow{3}{*}{ PAT } & & \multirow{3}{*}{51} & \multirow{3}{*}{$\begin{array}{c}\text { I5 } 77468 \\
4620\end{array}$} & $I^{3}$ & 1 End. IGB \\
\hline & & c.2947delA & & & \multirow{2}{*}{56} & & & $2^{5}$ & 1 Len, $1 \mathrm{~GB}$ \\
\hline & & & & & & & & $3^{\circ}$ & 1 Sto \\
\hline \multirow{3}{*}{ p8 } & \multirow{3}{*}{$\mathrm{CDHI}$} & \multirow{3}{*}{$\begin{array}{c}\text { c. } 2359 \mathrm{G}>\mathrm{A} \\
\text { (p.Val787De) }\end{array}$} & \multirow{3}{*}{ MS } & \multirow{3}{*}{ vUS } & & & & $I^{p}$ & - \\
\hline & & & & & 35 & 35 & $\begin{array}{ll}15 / 0027 \\
0336\end{array}$ & $2^{\sigma}$ & 2 Bre, 1 Lung \\
\hline & & & & & & & & $3^{\circ}$ & - \\
\hline & POLDI & & & & & & & $I^{s}$ & $1 \mathrm{P}, 1 \mathrm{Bre}, 1 \mathrm{MM}$ \\
\hline pg & 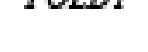 & (D.Val765Met) & MS & VUS & 59 & 50 & 0487 & $2^{6}$ & 1 Bra, 1 Lung \\
\hline & & & & & & & & & - \\
\hline & $A T M$ & & & & & & & $\Gamma^{5}$ & $1 \mathrm{Bre}$ \\
\hline P10 & AMA & C.0809A & MS & vUS & 63 & 54 & 1515531 & $2^{5}$ & 1 End, 1 Colon \\
\hline & & & & & & & & $3^{\prime \prime}$ & I Bre, 1 Lung \\
\hline & & & & & & & & $r^{6}$ & 1 Bre \\
\hline P12 & $R E T$ & $\begin{array}{c}c .224 \mathrm{C}>\mathrm{T} \\
\text { (p. Thr } 75 \mathrm{Met})\end{array}$ & MS & vUS & 33 & 33 & $\begin{array}{l}\mathrm{r} 514264 \\
1173\end{array}$ & $\frac{2}{2^{s}}$ & 1 Colon \\
\hline & & & & & & & & $3^{5}$ & $1 \mathrm{~Pa}$ \\
\hline & & $\mathrm{C} .545 \mathrm{G}>\mathrm{A}$ & & & & & & $\overline{1}^{5}$ & $1 \mathrm{Bre}$ \\
\hline $\mathrm{P} 13$ & MUTYH & (p.Arg182His) & MS & PAT & 55 & 48 & $\begin{array}{c}\mathrm{rs} 14335 \\
3451\end{array}$ & $2^{6}$ & $1 \mathrm{MM}$ \\
\hline & & & & & & & & $3^{\sigma}$ & $1 \mathrm{~GB}$ \\
\hline & & & & & & & 558778 & $I^{5}$ & $1 \mathrm{HL}+\mathrm{Bre}, 1 \mathrm{Lrx}$ \\
\hline P15 & BRIPI & $c .326 \mathrm{~A}>\mathrm{G}$ & MS & VUS & 62 & 49 & 2734 & $2^{s}$ & 1 End,2 Bre,1Sto \\
\hline & & (p.Asnl09Ser) & & & & & & $3^{5}$ & 1Leu,1Skin,1Bre \\
\hline & & & & & & & & $\underline{I}$ & $1 \mathrm{Bre}, 1 \mathrm{Pr}$ \\
\hline $\mathbf{p}_{20}$ & $R L N T I$ & $c .1333+1 \mathrm{G}>\mathrm{A}(\mathrm{p} . ?)$ & SE & VUS & 43 & 38 & 0359 & $2^{*}$ & 1 End \\
\hline & & & & & & & & $\frac{3}{n^{2}}$ & $\frac{-}{18 \operatorname{lng}}$ \\
\hline $\mathrm{p}_{21}$ & MIHI & $\mathrm{c} .1876 \mathrm{~T}>\mathrm{C}$ & MS & VUS & 62 & 26 & I537724 & $\frac{1^{*}}{\gamma^{s}}$ & 1 Bre, 1 Colon \\
\hline 821 & BALAI & (p.Phe626Leu) & 210 & vos & 02 & & 1633 & & 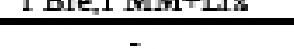 \\
\hline P23 & & & & & & 52 & & $I^{3}$ & 1 PI, 1 GB \\
\hline+23 & FANCC & c. $844-1 G>C(p . ?)$ & SE & PAT & 60 & & $\begin{array}{c}15 / 7420 \\
9201\end{array}$ & & $10 \mathrm{vary}, 1 \mathrm{~GB}, 1 \mathrm{Es}$ \\
\hline & & & & & & & & & 1 Colon, 1 Larenx \\
\hline & & & & & & 43 & & $\Gamma^{5}$ & $1 \mathrm{Pr}$ \\
\hline P24 & MREIIA & (p.Ser273Cys) & MS & vUS & 50 & 43 & $\begin{array}{c}1514340 \\
0546\end{array}$ & $2^{5}$ & $1 \mathrm{Bre}$ \\
\hline & & & & & & & & 3 & - \\
\hline Do4 & 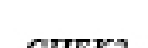 & $c .944 \mathrm{G}>\mathrm{A}$ & Me & 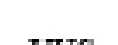 & 50 & 43 & 5515559 & $I^{\circ}$ & $1 \mathrm{p}_{\mathrm{T}}$ \\
\hline $\mathrm{P}_{24}$ & CHEK 2 & (p.Gly315Glu) & MS & vus & 50 & & 15471 & $\frac{2^{5}}{v^{2}}$ & $1 \mathrm{Bre}$ \\
\hline & & & & & & & & $T^{5}$ & 1 MDS, 1 Colon \\
\hline p25 & CHEK2 & c. $1389 \bigcirc \mathrm{A}$ & NS & PAT & 45 & 44 & I576220 & $\frac{1}{2^{6}}$ & 1 Bre, 1 Lnnz, 1 Sto \\
\hline & & & & & & & & & \\
\hline & & & & & & 45 & 1575287 & $I^{5}$ & $1 \mathrm{Bre}, 1 \mathrm{MM}$ \\
\hline p26 & B.ARDI & (D.Arg43Glv) & MS & vUS & 52 & & 1324 & $2^{\prime}$ & - \\
\hline & & & & & & & & $3^{6}$ & 1 Colon \\
\hline & & & & & & 39 & & $I^{2}$ & 1 Lung \\
\hline P27 & $R E T$ & (p.Glu210Lys) & MS & VUS & 44 & & 00762 & $2^{*}$ & 1 Bre, 1 Sto \\
\hline & & & & & & & & & 1 Bre \\
\hline p36 & $R A D 50$ & c. $2177 \mathrm{G}>\mathrm{A}$ & Me & עחד & 55 & 48 & I528903 & $1^{s}$ & 1 Lung, $1 \mathrm{Pr}$ \\
\hline & & (p.Arg726His) & & vus & 33 & & 092 & $\frac{2}{3^{2}}$ & $1 \mathrm{Bre}$ \\
\hline P37 & PM/S2 & c. $1999 \mathrm{G}>\mathrm{A}$ & MS & VUS & 50 & 45 & I558778 & $I^{5}$ & 1 Lung \\
\hline
\end{tabular}


DÜZKALE ve ark.

\begin{tabular}{|c|c|c|c|c|c|c|c|c|c|}
\hline & & (p.Glu667Lys) & & & & & 0045 & $2^{0}$ & 1 Bre, 1 Sto, 1 Lrx \\
\hline & & & & & & & & $3^{0}$ & - \\
\hline \multirow{3}{*}{ P41 } & \multirow{3}{*}{$A T M$} & \multirow{3}{*}{$\begin{array}{c}\text { c.2573T }>\text { A } \\
\text { (p.Phe858Tyr) }\end{array}$} & \multirow{3}{*}{ MS } & \multirow{3}{*}{ VUS } & \multirow{3}{*}{46} & \multirow{3}{*}{45} & \multirow{3}{*}{ - } & $1^{0}$ & 2 Bre \\
\hline & & & & & & & & $2^{0}$ & \\
\hline & & & & & & & & $3^{0}$ & 1 Bre \\
\hline \multirow{3}{*}{$\begin{array}{c}\mathrm{P} 42 \\
*\end{array}$} & \multirow{3}{*}{$P A L B 2$} & \multirow{3}{*}{ c. $211+1 \mathrm{G}>\mathrm{T}(\mathrm{p} . ?)$} & \multirow{3}{*}{ SE } & \multirow{3}{*}{ PAT } & \multirow{3}{*}{37} & \multirow{3}{*}{37} & \multirow{3}{*}{$\begin{array}{c}\text { rs } 15554 \\
62026\end{array}$} & $1^{0}$ & 1 End \\
\hline & & & & & & & & $2^{0}$ & 2 End, $1 \mathrm{~Pa}, 1 \mathrm{Pr}$ \\
\hline & & & & & & & & $3^{0}$ & - \\
\hline \multirow{3}{*}{ P43 } & \multirow{3}{*}{$M E T$} & \multirow{3}{*}{$\begin{array}{c}\text { c.142G }>\text { A } \\
\text { (p.Ala48Thr) }\end{array}$} & & & & & & $1^{0}$ & $1 \mathrm{Bre}$ \\
\hline & & & MS & VUS & 64 & 49 & $\begin{array}{c}\text { rs3 } / 405 \\
0750\end{array}$ & $2^{0}$ & 1 Colon, 1 Sto \\
\hline & & & & & & & & $3^{0}$ & \\
\hline & & & & & & & & $1^{0}$ & 1 Colon \\
\hline $\begin{array}{c}\mathrm{P} 45 \\
*\end{array}$ & $A T M$ & $\begin{array}{c}\text { c.81241>A } \\
\text { (n Asn2708Glu) }\end{array}$ & MS & PAT & 51 & 33 & $\begin{array}{c}\operatorname{rs} 58778 \\
1990\end{array}$ & $2^{0}$ & 1 Thyroid \\
\hline & & & & & & & & $3^{0}$ & 2 Bre, 1 Colon \\
\hline & & & & & & & & $1^{0}$ & 1 Parathyroid \\
\hline P47 & $R A D 51 B$ & $\begin{array}{c}c .1155 \mathrm{~A}>1 \\
\text { (p. Ter385Tyrext*64) }\end{array}$ & NS & VUS & 56 & 42 & $\begin{array}{c}\text { rs89290 } \\
4253\end{array}$ & $2^{0}$ & 1 End \\
\hline & & & & & & & & $3^{0}$ & - \\
\hline & & & & & & & & $1^{0}$ & 1 End \\
\hline P48 & $S M A R C A 4$ & $\begin{array}{c}\mathrm{c} .4930 \mathrm{G}>\mathrm{A} \\
\text { (n.Glv1644Ser) }\end{array}$ & MS & VUS & 43 & 43 & $\begin{array}{c}\text { rs37231 } \\
9442\end{array}$ & $2^{0}$ & 1 Larenx, 1 Bra \\
\hline & & & & & & & & $3^{0}$ & 2 Bra, 1 Colon \\
\hline & & & & & & & & $1^{0}$ & 1 End \\
\hline P48 & MSH6 & $\begin{array}{c}\text { c. } 1729 \mathrm{C}>\mathrm{I} \\
\text { (n Arg577 Cvs) }\end{array}$ & MS & VUS & 43 & 43 & $\begin{array}{c}\text { rs54283 } \\
8372\end{array}$ & $2^{0}$ & 1 Larenx, $1 \mathrm{Bra}$ \\
\hline & & & & & & & & $3^{0}$ & 2 Bra, 1 Colon \\
\hline & & & & & & & & $1^{0}$ & 1 Bre \\
\hline P49 & POLE & $\begin{array}{c}\text { c. } 5668 \mathrm{~A}>\mathrm{G} \\
(\mathrm{flle} 1890 \mathrm{Val})\end{array}$ & MS & VUS & 77 & NA & $\begin{array}{c}\mathrm{rs} / 4580 \\
4140\end{array}$ & $2^{0}$ & $1 \mathrm{MaM}$ \\
\hline & & & & & & & & $3^{0}$ & - \\
\hline & & & & & & & $r_{s} 92290$ & $1^{0}$ & $1 \mathrm{Bre}$ \\
\hline P49 & GEN1 & (n Tyr161Cys) & MS & VUS & 77 & NA & $\begin{array}{c}\text { rs92290 } \\
5215\end{array}$ & $2^{0}$ & $1 \mathrm{MaM}$ \\
\hline & & & & & & & & $3^{0}$ & - \\
\hline & & & & & & & & $1^{0}$ & NA \\
\hline$*$ & CHEK2 & (n.Thr476Met) & MS & L.PAT & 39 & 36 & $\begin{array}{c}\mathrm{rs} 142 / 6 \\
3740\end{array}$ & $2^{0}$ & NA \\
\hline & & & & & & & & $3^{0}$ & NA \\
\hline & & & & & & & & $1^{0}$ & 1 Sto \\
\hline * & CHEK2 & (p.Thr476Met) & MS & L.PAT & 42 & 40 & $\begin{array}{c}\text { rs } 14276 \\
3740\end{array}$ & $2^{0}$ & 1 Sto \\
\hline & & & & & & & & $3^{0}$ & - \\
\hline & & & & & & & & $1^{0}$ & - \\
\hline P54 & $\mathrm{CDH} 1$ & (n Aro $796 \mathrm{Gln})$ & MS & VUS & 42 & 39 & $\begin{array}{c}\text { rs58/78 } \\
2549\end{array}$ & $2^{0}$ & 1 Bre, 1 Liver \\
\hline & & & & & & & & $3^{0}$ & 1 Sto \\
\hline & & & & & & & & $1^{0}$ & 1 Per, 1 Bre, \\
\hline P57 & MSH2 & $\begin{array}{c}\mathrm{c} .4351>\mathrm{G} \\
(\mathrm{n} \text { Ile145Met) }\end{array}$ & MS & VUS & 45 & 40 & $\begin{array}{c}\mathrm{rs} 63 / 50 \\
124\end{array}$ & $2^{0}$ & 1 Bre \\
\hline & & & & & & & & $3^{0}$ & 2 Bre \\
\hline & & & & & & & & $1^{0}$ & - \\
\hline P58 & $B R I P 1$ & $\begin{array}{l}\text { c. } 31 / 8 \mathrm{U}>\mathrm{A} \\
\text { (p.Val1060Ile) }\end{array}$ & MS & VUS & 46 & 43 & $\begin{array}{l}\text { rsi4901 } \\
6505\end{array}$ & $2^{0}$ & - \\
\hline & & & & & & & & $3^{0}$ & 1 End, 1 Bre \\
\hline & & & & & & & & $1^{0}$ & 2 Bre \\
\hline $\begin{array}{l}105 \\
*\end{array}$ & $P A L B 2$ & c.557dup (p.Asn186fs) & FS & PAT & 58 & 58 & $\begin{array}{l}1515534 \\
61727\end{array}$ & $2^{0}$ & 2 Bre \\
\hline & & & & & & & & $3^{0}$ & - \\
\hline & & & & & & & & $1^{0}$ & - \\
\hline P64 & $A T M$ & $\begin{array}{l}\text { c. } 2021 \mathrm{~A}>\mathrm{U} \\
\text { (n. His674Arg) }\end{array}$ & MS & VUS & 73 & 69 & $\begin{array}{l}\text { rS } 201 / 0 \\
2714\end{array}$ & $2^{0}$ & 1 Colon \\
\hline & & & & & & & & $3^{0}$ & - \\
\hline
\end{tabular}


Tablo 3: Nedensel gen taşıyıcılığınun, değişkenler ile ilişkisi

\begin{tabular}{|c|c|c|c|}
\hline Değiģken & $\begin{array}{c}\text { Nedensel gen taşıyıcısı } \\
\text { olmayanlar } \\
\mathrm{N}=57\end{array}$ & $\begin{array}{c}\text { Nedensel gen taģıyıcisı } \\
\text { olanlar } \\
\mathrm{N}=9\end{array}$ & $\begin{array}{c}\text { Istatistiksel } \\
\text { anlamlıhk düzeyi } \\
\text { (p)* }\end{array}$ \\
\hline Yaş, ortanca (IQR) & $42(39-46)$ & $44(37-51)$ & 0,594 \\
\hline \multicolumn{4}{|l|}{ Tūmōr lokalizasyon } \\
\hline$\widehat{\text { Sağ }}$ & $28(49,1)$ & $5(55,6)$ & 0,879 \\
\hline Sol & $\overline{28(49,1)}$ & $4(44,4)$ & \\
\hline Bilateral & $1(1,8)$ & $0(0)$ & \\
\hline \multicolumn{4}{|l|}{ Histopatoloji } \\
\hline Invaziv duktal & $41(71,7)$ & $6(66,7)$ & $\overline{-}$ \\
\hline Duktal in situ karsinoma & $9(15,8)$ & $0(0)$ & \\
\hline Invaziv lobūler & $1(1,8)$ & $\overline{0(0)}$ & \\
\hline Lobūler in situ karsinoma & $1(1,8)$ & $0(0)$ & \\
\hline Mikst karsinoma & $3(5,3)$ & $2(22,2)$ & \\
\hline Müsinöz & $1(1,8)$ & $1(11,1)$ & \\
\hline Papiller & $1(1,8)$ & $\overline{0(0)}$ & \\
\hline \multicolumn{4}{|l|}{ Ostrojen reseptōrü } \\
\hline Pozitif & $\overline{48(84,2)}$ & $0(0)$ & 0,341 \\
\hline Negatif & $9(15,8)$ & $9(100)$ & \\
\hline \multicolumn{4}{|l|}{ Progesteron reseptörū } \\
\hline Pozitif & $48(84,2)$ & $3(33,3)$ & 0,347 \\
\hline Negatif & $9(15,8)$ & $6(66,7)$ & \\
\hline \multicolumn{4}{|l|}{ c-erbB2 } \\
\hline 0 & $10(17,5)$ & $2(22,2)$ & 0,469 \\
\hline 1 & $9(15,8)$ & $0(0)$ & \\
\hline 2 & $10(17,5)$ & $3(33,3)$ & \\
\hline 3 & $28(49,1)$ & $4(44,4)$ & \\
\hline Grade & & & \\
\hline
\end{tabular}

ID, Hasta barkod numarası, yıldızlı işaretlenen nedensel varyant tespit edilen hastalardır; Nük, Nükleotid; AA, Aminoasit; Lok, Lokalizasyon; Family History, This column shows the number of individuals with retinopathy in relatives; AA, aminoacid; Lok:Varyantın gende yerleştiği bölge; E: Ekzon; I:Intron; FS, çerçeve kayması; MS, missense; NS, nonsense; RE, düzenleyici; SE, splice etki; S, sinonim, P, patojenik; LP, muhtemel patojenik; Akrabalarda kanser öyküsü sütunu, incelenen 3 kuşak pedigri analiz notlarından elde edilmiştir. Bu sütunda, kanserli akrabaların sayısı ve kanserlerinin türü sunulmuştur; MM, Multipl Myeloma; MaM, Malign Melanoma; End, Endometrium; Pa, Pankreas; Es, Özofagus; GB, Safra kesesi; Per, Periton; Lrx, Larinks; Pr, Prostat; HL, Hodgkin Lenfoma; Bre, Meme; Bra, Beyin; Leu, Lösemi; Sto, Mide; Genomik varyantlar için tercih edilen transkript numaraları: NM_005431.2 (XRCC2), NM_032043.3 (BRIP1), NM_004360.5 (CDH1), NM_001256849.1 (POLD1), NM_000051.4 (ATM), NM_020975.6 (RET), NM_001128425.2 (MUTYH), NM_032043.3 (BRIP1), NM_021930.6 (RINT1), NM_000249.4 (MLH1), NM_000136.3 (FANCC), NM_005591.4 (MRE11A), CHEK2 (NM_007194.4), BARD1 (NM_000465.4), NM_020975.6 (RET), NM_005732.4 (RAD50), NM_000535.7 (PMS2), NM_000051.4 (ATM), NM_024675.4 (PALB2), NM_001127500.3 (MET), NM_006218.4 (PIK3CA), NM_133509.4 (RAD51B), NM_001128849.3 (SMARCA4), NM_000179.3 (MSH6), NM_006231.4 (POLE), NM_182625.5 (GEN1), NM_007194.4 (CHEK2), NM_130799.2 (MEN1), NM_000251.3(MSH2), NM_032043.3(BRIP1). 
DÜZKALE ve ark. Meme kanserine yatkınlık genlerinin araştırılması

\begin{tabular}{|c|c|c|c|}
\hline 1 & $7(12,3)$ & $1(11,1)$ & 0,485 \\
\hline 2 & $20(35,1)$ & $5(55,6)$ & \\
\hline 3 & $30(52,6)$ & $3(33,3)$ & \\
\hline \multicolumn{4}{|c|}{ Tanı anında metastaz } \\
\hline Yok & $39(68,4)$ & $5(55,6)$ & 0,467 \\
\hline Var & $18(31,6)$ & $4(44,4)$ & \\
\hline \multicolumn{4}{|c|}{$\begin{array}{l}\text { Akrabalarda yalnız meme kanserli } \\
\text { birey sayısı }\end{array}$} \\
\hline Yok & $13(22,8)$ & $4(44,4)$ & 0,383 \\
\hline $1-2$ & $34(59,7)$ & $4(44,4)$ & \\
\hline 3 ve üzeri & $10(17,5)$ & $1(11,1)$ & \\
\hline \multicolumn{4}{|c|}{$\begin{array}{l}\text { Akrabalarda kanserli birey sayıs1 } \\
\text { (kanserin tüm türleri) }\end{array}$} \\
\hline 0 & $1(1,8)$ & $0(0)$ & 0,545 \\
\hline $1-2$ & $17(29,8)$ & $1(11,1)$ & \\
\hline $3-5$ & $33(57,9)$ & $6(66,7)$ & \\
\hline 6 ve üzeri & $6(10,5)$ & $2(22,2)$ & \\
\hline
\end{tabular}

*Bağımsız kategorik değişkenlerin karşılaştırılmasında ki-kare veya Fisherin Exact testi kullanıldı ve normal dağılıma uymayan iki grup verilerinin karşılaştırılmasında Mann-Whitney U testi kullanıldı. İstatistiksel anlamlılık düzeyi olan p değeri, karşılaştırılan tüm parametreler açısından anlamlı bulunamadı.

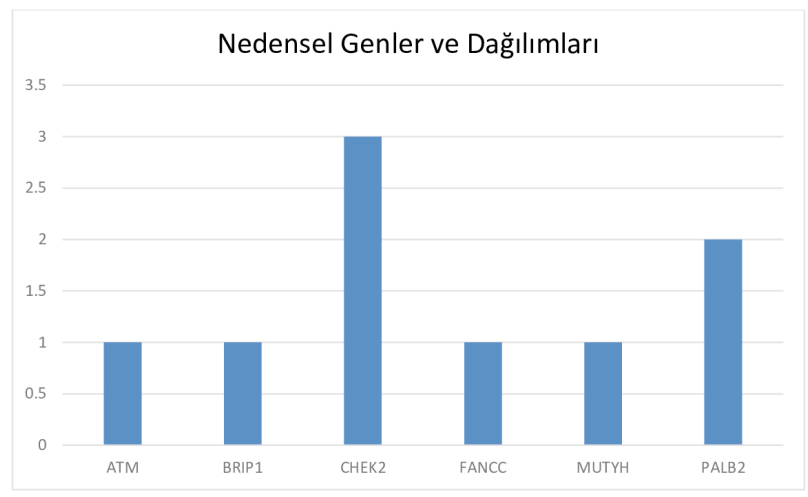

Şekil 1: Çalışmada saptanan nedensel genler. Çalışmada saptanan nedensel genler; ATM (1/9, \%11), BRIP1 (1/9, \%11), CHEK2 (3/9, \%34), FANCC $(1 / 9, \% 11)$, MUTYH $(1 / 9, \% 11)$ ve PALB2 $(2 / 9, \% 22)$ olarak saptandı.

\section{Tartışma}

Genel toplum insidansı \%12 olan meme kanseri ile ilgili gerçekleştirilen epidemiyolojik çalışmalar, meme kanserli olan kadınların birinci derece kadın akrabalarının, genel popülasyona kıyasla, hastalığa yakalanma riskinin yaklaşık iki kat daha fazla olduğunu göstermiştir $[9,10]$. Bu kanser türünün paylaşlan çevresel, genetik faktörlerden veya her ikisinden de kaynaklanabileceği düşünülse de, yapılan ikiz çalışmaları ile ailesel riskin çoğunlukla kalıtsal yatkınlık nedeniyle olduğunu kanıtlanmıştır [4, 10]. Güçlü meme kanseri öyküsü olan ailelerde, kalıtsal yatkınlık faktörlerinden en iyi bilinenleri BRCA1 ve BRCA2 genleridir [11]. BRCA1/2, tümör baskılayıcı genler olarak işlev görür ve genomik stabilitenin korunmasını sağlarlar. Her iki gen de, RAD51 ileetkileşimegirerekhomolog rekombinasyonyoluyla çift sarmal kırılmaların onarımında rol oynarlar [12]. Yapılan 
çalışmalarda BRCA1/2 genlerinden başka, meme kanserine yatkınlık oluşturan birçok gen tanımlanmıştır. Bu genler meme kanserinde penetrasyon seviyelerine göre (sözkonusu genin, fenotipik olarak ifade edilmesinin istatistiksel oranı); yüksek, orta ve düşük penetrasyonlu olarak sınıflandırılmıştır (Şekil 2). BRCA1/2 ve TP53 gibi yüksek penetranslı genlere ait nedensel varyantlar, popülasyonda \%0,1'den daha az taşıyıcılık frekansı ile nadir görülen ve meme kanseri riskini 10-20 kat artıran genomik değişimlerdir. Buna karşın ATM, BRIP1, CHEK2, PALB2 gibi orta düzeyde meme kanser yatkınlık genlerinin nedensel varyantlarının popülasyon taşıyıcılık frekansları \%0,6'dan daha az sıklıktadır ve meme kanser riskinde 2-4 kat artışa neden olmaktadırlar [4]. Yüksek ve orta düzeyde penetrasyon gösteren bu genler dışında, bazı genlere ait daha yaygın gözlenen (popülasyon frekansı \%5-50 civarında olan), bazı düşük penetranslı meme kanser yatkınlık alleleri de literatürde tanımlanmıştır. Bu alleler, son yıllarda gerçekleştirilen "genom çapında etiket SNP (genome-wide tag SNP) araştırmaları" sonucunda keşfedilmiştir. Günümüzde çok sayıda vaka/ kontrolden oluşan birleşik setlerden elde edilen veriler, yedi allellin, düşük penetranslı meme kanser yatkınlık alleli olduğunu onaylamıştır. Bunlardan beşi, bilinen protein kodlayan genleri kapsayan "bağlantı dengesizliği (linkage disequilibrium)" bölgelerinde ve kalan ikisi ise, bilinen protein kodlayan genlerin olmadığı bölgelerde lokalizedir. Bu alleler; rs2981582 (FGFR2, 10q), rs3803662 (TOX3, 16q), rs889312 (MAP3K1, 5q), rs3817198 (LSP1, 11p), rs13281615 (8q), rs13387042 (2q), rs1045485 (CASP8_D302H) olarak sıralanabilir. Düşük penetranslı alleleri heterozigot olarak taşıyanlarda meme kanseri göreceli riskinin yaklaşık 1,25 kat, homozigot olarak taşıyanlarda ise 1,65 kat artmış olduğu düşünülmektedir [13, 14]. Çalışmamızdaki mutasyon taşıyıcısı olan 9 hastanın 3'ünün nedensel geni CHEK2 idi. Bu gen tarafından ifade edilen ve bir serin/treonin kinaz olan CHEK2 kinaz, DNA hasarına yanıt veren hücresel ağın ayrılmaz bir bileşeni olarak genomik bütünlüğün korunmasına ve potansiyel olarak zararlı mutasyonların önlenmesine yardımcı olur. Yapılan çalışmalar, CHEK2'nin bir tümör baskılayıcı rolü olduğunu ve mutasyonlarının çeşitli kanser türlerine yatkınlık oluşturabileceğini güçlü bir şekilde göstermektedir. Moleküler düzeyde, CHEK2 geninin mutasyonları ya CHEK2 ekspresyonunun kaybına yol açar ya da CHEK2'nin bir sinyal molekülü olarak işlevini zayıflatır [15]. CHEK2 mutasyonları, meme kanseri dahil olmak üzere, kolorektal kanser, testis germ hücre tümörleri, renal hücreli kanser, prostat kanseri gibi diğer kanserlerle de ilişkili bulunmuştur [16]. Mevcut Ulusal Kapsamlı Kanser Ağı (NCCN) kılavuzları, bu nedenle CHEK2 mutasyon taşıyıcısı olan kadınlarda 40 yaşından itibaren yıllık mamografi ve meme MRI değerlendirilmesini önermektedir. Aynı kılavuz, ne kendisinde ne de birinci derece akrabasında kolorektal kanser bulunmayan CHEK2 mutasyon taşıyıcılarının da, 40 yaşından başlayarak her 5 yılda bir kolonoskopi taramasını önermektedir [17]. Bizim çalışmamızda da CHEK2 mutasyonu bulduğumuz hastalara genetik danışmanlık verilerek takip altına alınmıştır.

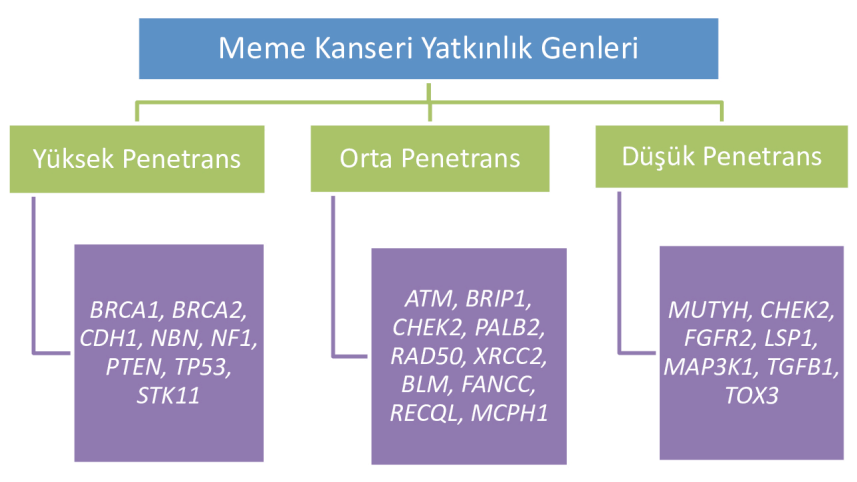

Şekil 2: Meme kanserinde penetrasyon düzeylerine göre, yatkınlık genlerinin sınıflandırılması

Çalışmadaki 2 hastada PALB2 geninde mutasyon saptanmıştır. PALB2, nükleer odaklarda BRCA2'ye bağlanarak birlikte lokalize tümör baskılayıcı olarak işlev gören bir proteini kodlar. PALB2, çekirdekte BRCA2'nin lokalizasyonuna izin verir ve BRCA1PALB2-BRCA2 kompleksi için moleküler yapı iskeleti sağlar. PALB2, hücrelerin DNA hasarını biriktirmesini önlemek için yalnızca BRCA2 ile çalışmakla kalmaz, aynı zamanda BRCA2 ile etkileşime girerek replikasyon proteini $A^{\prime} y ı$ işlenmiş tek sarmallı DNA ucunda RAD51 ile değiştirir. PALB2'nin monoallelik mutasyonlarıkanserlerlesonuçlanabilirken, bialelikmutasyonları “Fanconi anemisi komplementasyon (tamamlayıcı) grup N'ye yol açar [18]. Heterozigot PALB2 mutasyon taşıyıcılarında meme kanseri ve pankreas kanseri riski artmıştır. Yapılan çalışmalar PALB2 germ hattı mutasyonları yaşam boyu meme kanseri için orta derecede artmış bir risk sağlarken, 30 yaş ve altındakilerde yaşa özgü göreceli riskte büyük ölçüde bir artış gözlenmiştir. PALB2 mutasyon taşıyıcılarındaki pankreas kanseri riski ise henüz tam olarak belirlenmemiştir [19-21]. Çalışmamızdaki hastalardan birinde, BRIP1 geninde nedensel bir varyant tespit edilmiştir. BRIP1 (BRCA1 ile etkileşime giren protein C-terminal helikaz 1), Fanconi anemi (FA) yolağının bir üyesidir ve DNA çapraz bağlarının onarımı için bu genin aktivitesi gereklidir ve genom stabilitesinin sürdürülmesinde oldukça önemlidir. FA yolağının diğer üyeleri olan BRCA1 ve BRCA2'deki mutasyonların yol açtığı gibi, BRIP1 mutasyonlarının da over ve meme kanseri 
gelişimi için risk artışına yol açtığı düşünülmektedir [22]. Çalışmadaki bir hastada MUTYH geninde, muhtemel patojenik bir varyant tespit edilmiştir. MUTYH geni, baz eksizyon onarım mekanizması yoluyla DNA hasarını onaran MYH glikozilaz enzimini ifade etmektedir. MUTYH, DNA hasarına yanıt olarak baz eksizyon onarımı ve apoptozu başlatsa da, birincil işlevi oksidatif DNA hasarını onarmaktır [23]. Bu genin homozigot ve bialelik mutasyon taşıyıcılarının kolorektal kanser açısından yüksek riske sahip olduğu bildirilmiştir, ancak heterozigot taşıyıcı kadınlarda meme kanseri riskiyle alakalı literatürde çelişkili yayınlar bulunmaktadır [24]. Bu çelişkili sonuçlara rağmen, MUTYH heterozigot taşıyıcı kadınlara, olası artan meme kanseri riskleri ve bu kanseri önlemeye yönelik genel önlemler hakkında danışmanlık verilmesi gerektiği düşünülmektedir [24].

Çalışmada bir diğer hastada ise, FANCC geninde nedensel bir varyant tespit edilmiştir. FANCC geni; protein ürünleri bir multiprotein çekirdek kompleksinde fiziksel olarak etkileşime giren, bir grup klasik Fanconi anemi genlerinden biridir. Bu genin, diğer bazı Fanconi anemi genleri ile birlikte toll benzeri reseptör yolunu modüle ettiği ve hematopoietik hücrelerde hücre döngüsünün bütünlüğünü koruduğu tespit edilmiştir. FA genlerinde heterozigotluğun meme ve diğer kanserlerle ilişkileri bildirilmiş olmasına rağmen, FANCD1/BRCA2 dışındaki Fanconi genlerinden herhangi birinin heterozigot taşıyıcılarının kanser gelişimi açısından yüksek risk altında olup olmadığı halen gizemini korumaktadır $[3,4,9]$.

Çalışmadaki hastalardan birinde ATM nedensel varyantı tespit edilmiştir. ATM (Ataksi telenjiektazi ile mutasyona uğramış) gen, hasarlı DNA'nın onarımında ve hücre döngüsünün düzenlenmesinde oynar. Yetişkin popülasyonun \%1-2'sinde patojenik ATM varyantları, heterozigot olarak taşınmaktadır [25]. Yapılan meta-analiz sonuçları, ATM geni nedensel varyantlarının meme kanseri insidansını artırdığını ve bu varyantları taşıyan kişilerin meme kanserine yakalanma riskinin arttığını göstermektedir. Bu heterozigot kadınlarda yaşam boyu meme kanseri riskinin \%25'den fazla olabileceği tahmin edilmektedir. Bundan dolayı, bu kadınlara 40 yaşından itibaren yıllık mamografi taramaları önerilmektedir. Aile öyküsüne göre, hem mamografi hem de MRI ile taramanın daha erken başlaması düşünülebilir [25].

\section{Sonuç}

Günümüzde, aynı anda birden fazla genin dizilenmesine olanak veren çoklu gen testleri sayesinde gerçekleştirilen detaylı ve yoğun moleküler araştırmalara rağmen, halen meme kanserli ailelerin \%70'inden fazlasında genetik etiyopatogenez açıklanamamaktadır. Güçlü bir kanserli akraba geçmişine sahip bu ailelerde hastalığın nedeni tam olarak açıklanamamaktadır. Bu vakaların bir kısmı, çevresel risk faktörlerine atfedilebilir veya meme kanseri yaygın bir hastalık olduğundan, sporadik meme kanseri vakaları rastgele bir araya gelmiş de olabilir. Çalışmamızda, BRCA1/2 normal olan meme kanserli kadınlarda, incelenen diğer kanser yatkınlık genleri \%13,63 oranında tespit edilmiştir. Bu araştırmada 59 ve 27 gen içeren 2 ayrı panel kullanılmış olup bu panellerin kapsadıkları genler sayıca oldukça farklı olmasına rağmen her iki panelin nedensel genleri tespit edebilme başarı oranları (\%44 ve \%55) birbirine yakın olarak saptanmıştır. Sonuç olarak, çoklu gen testleri ile kalıtsal kanserlerde risk altındaki hastaların tespit edilmesi bu bireylerin uygun tanı, izlem, tarama ve tedavi programına dahil edilmesinde avantaj sağlar.

\section{Maddi Destek ve Çıkar İlişkisi}

Çalışmayı maddi olarak destekleyen kişi/kuruluş yoktur ve yazarların herhangi bir çıkar dayalı ilişkisi yoktur.

\section{Kaynaklar}

1. Jemal A, Bray F, Center MM, Ferlay J, Ward E, Forman D. Global cancer statistics. CA Cancer J Clin 2011; 61: 69-90.

2. Broca P. Traité des tumeurs. Vols. 1 and 2. Paris: Asselin; 1866-9

3. Honrado E, Benítez J, Palacios J. The molecular pathology of hereditary breast cancer: genetic testing and therapeutic implications. Mod Pathol 2005; 18: 1305-20

4. Stratton MR, Rahman N. The emerging landscape of breast cancer susceptibility. Nat Genet 2008; 40: 17-22.

5. Vargas AC, Reis-Filho JS, Lakhani SR. Phenotype-genotype correlation in familial breast cancer. J Mammary Gland Biol Neoplasia 2011; 16: 27-40.

6. Beck AC, Yuan $\mathrm{H}$, Liao J et al. Rate of BRCA mutation in patients tested under NCCN genetic testing criteria. Am J Surg 2020; 219: 145-9.

7. Elston CW, Ellis IO. Pathological prognostic factors in breast cancer. I. The value of histological grade in breast cancer: experience from a large study with long-term follow-up. Histopathology 1991; 19: 403-10.

8. Richards S, Aziz N, Bale $S$ et al. Standards and guidelines for the interpretation of sequence variants: a joint consensus recommendation of the American College of Medical Genetics and Genomics and the Association for Molecular Pathology. Genet Med 2015; 17: 405-24. 
9. Thompson D, Easton D. The genetic epidemiology of breast cancer genes. J Mammary Gland Biol Neoplasia 2004; 9: 221-36.

10. Peto J, Mack TM. High constant incidence in twins and other relatives of women with breast cancer. Nat Genet 2000; 26: 411-4.

11. Gerdes AM, Cruger DG, Thomassen M, Kruse TA. Evaluation of two different models to predict BRCA1 and BRCA2 mutations in a cohort of Danish hereditary breast and/or ovarian cancer families. Clin Genet 2006; 69: 171-8.

12. Roy R, Chun J, Powell SN. BRCA1 and BRCA2: different roles in a common pathway of genome protection. Nat Rev Cancer 2011 12: 68-78.

13. Easton DF, Pooley KA, Dunning AM et al. Genome-wide association study identifies novel breast cancer susceptibility loci. Nature 2007; 447: 1087-93.

14. Cox A, Dunning AM, Garcia-Closas M et al. A common coding variant in CASP8 is associated with breast cancer risk. Nat Genet 2007; 39: 352-8.

15. Nevanlinna H, Bartek J. The CHEK2 gene and inherited breast cancer susceptibility. Oncogene 2006; 25: 5912-9.

16. Rainville I, Hatcher S, Rosenthal E et al. High risk of breast cancer in women with biallelic pathogenic variants in CHEK2. Breast Cancer Res Treat. 2020; 180: 503-9.

17. NCCN clinical practice guidelines in oncology, genetic/familial high-risk assessment: breast and ovarian (version 3. 2019). https://www.nccn.org/professionals/physician_gls/pdf/ genetics_bop.pdf. (5 Haziran 2021).
18. Antoniou $A C$, Casadei $S$, Heikkinen $T$ et al. Breast-cancer risk in families with mutations in PALB2. N Engl J Med 2014; 371: 497-506.

19. Zhou J, Wang H, Fu F et al. Spectrum of PALB2 germline mutations and characteristics of PALB2-related breast cancer: Screening of 16,501 unselected patients with breast cancer and 5890 controls by next-generation sequencing. Cancer 2020; 126: 3202-8.

20. Antoniou AC, Casadei $S$, Heikkinen $T$ et al. Breast-cancer risk in families with mutations in PALB2. N Engl J Med 2014; 371: 497-506.

21. Janatová $M$, Borecká $M$, Soukupová J et al. PALB2 jako další kandidátní gen pro genetické testování u pa-cientů s hereditárním karcinomem prsu v České republice [PALB2 as Another Candidate Gene for Genetic Testing in Patients with Hereditary Breast Cancer in Czech Republic]. Klin Onkol 2016; 29: 31-4.

22. Weber-Lassalle N, Hauke J, Ramser J et al. BRIP1 loss-of-function mutations confer high risk for familial ovarian cancer, but not familial breast cancer. Breast Cancer Res 2018; 20: 7.

23. Mazouzi A, Battistini F, Moser SC et al. Repair of UV-Induced DNA Damage Independent of Nucleotide Excision Repair Is Masked by MUTYH. Mol Cell 2017; 68: 797-807.

24. Rennert G, Lejbkowicz F, Cohen I, Pinchev M, Rennert HS, Barnett-Griness O. MutYH mutation carriers have increased breast cancer risk. Cancer 2012; 118: 1989-93.

25. Jerzak KJ, Mancuso T, Eisen A. Ataxia-telangiectasia gene (ATM) mutation heterozygosity in breast cancer: a narrative review. Curr Oncol 2018; 25: 176-80. 